\title{
La información de sucesos. Temática en prensa escrita
}

Recibido: 31 de enero de 2011

Aceptado: 25 julio de 2011

Publicado: 31 de octubre de 2011
Rosa Rodríguez Cárcela rrodríguez@eusa.es Universidad de Sevilla (España)

Resumen: El artículo analiza y describe los contenidos temáticos de la información de sucesos $^{1}$ en la prensa escrita. El periodismo de sucesos pertenece al ámbito de la información periodística especializada, debido a la temática que trata y difunde. La mayoría de sus contenidos está referida a malas noticias, ya que sus dos categorías temáticas predominantes son los delitos y los siniestros, así como los homicidios, los accidentes de tráfico, el tráfico de drogas y los robos.

Palabras clave: Periodismo especializado, información de sucesos, temática, delitos, homicidios, siniestros, accidentes de tráfico, catástrofes naturales.

Abstract: The article analyzes and describes the thematic contents of incident reports in the press. Incident reports belong to the area of specialized journalism, because of the topic it deals and broadcasts. Most of its contents are related to bad news. The two major thematic categories of incident reports are crimes and accidents. The types of incidents that are mainly featured in the press are homicides, traffic accidents, drug dealing and burglary.

Key words: Specialized Journalism, Accident and Crime Reports, Subject, Crimes, Homicides, Accidents, Traffic accidents, Natural Disasters.

1.- Esta expresión (predominante en la Península) tiene como equivalentes en nuestra región a la "nota policial" y a la "crónica roja". 


\section{Introducción}

La información de sucesos es muy variada y compleja. Recoge contenidos de temáticas diferentes, pero reconocibles en la mayoría de los casos, ya que mayoritariamente son malas noticias: la comisión de delitos y faltas, las catástrofes naturales, los siniestros y los comportamientos humanos conflictivos o violentos. Asimismo, son sucesos todos aquellos hechos curiosos, sorprendentes o extravagantes que se salen de la norma habitual. Vamos a analizar sus contenidos y sus especializaciones temáticas más destacadas.

En el periodismo norteamericano existe una premisa que resume claramente el contenido de este tipo de noticias: Goods news are not news ("Las buenas noticias no son noticia"). Las "malas noticias" son siempre noticia y, debido a ello, el periodismo de sucesos es inseparable de la actividad periodística.

Los periodistas de sucesos cubren acontecimientos que se salen de lo habitual, como los homicidios, los robos, los siniestros y los hechos delictivos de cualquier naturaleza. Las noticias de sucesos acontecen a diario, el índice de delincuencia es elevado y publicar un periódico sin páginas que contengan este tipo de información especializada resulta actualmente imposible e inimaginable.

Se trata de información periodística especializada que, aunque menoscabada, es una de las más leídas en la prensa escrita. El periodismo de sucesos suele identificarse con el sensacionalismo; concepción errónea en la que también incurren los propios periodistas. Los sucesos son noticias que acontecen a diario y exigen un tratamiento serio y profesional, alejado de exageraciones y descripciones macabras. La información de sucesos es el periodismo en esencia y un tratamiento riguroso es contrario al sensacionalismo. Lo que ocurre es que la temática que trata puede degenerar en el sensacionalismo informativo.

Pese a la desaparición progresiva de la sección "de sucesos" en la prensa española, muchos de sus tópicos se siguen publicando diariamente en los periódicos, pero sin la distinción temática y tipográfica de antes. El criterio de ubicación de la información de sucesos se encamina actualmente hacia un criterio geográfico o territorial y no temático. Las noticias de sucesos han dejado de contar con una sección propia y aparecen dispersas en otras secciones. No obstante, la presencia de los sucesos en los periódicos es inevitable y, por ello, la prensa escrita continúa publicándolos, pero mezclados e incluso enmascarados en otras secciones periodísticas, siendo las más comunes las de "Sociedad", "Nacional" o "Local”, según el lugar donde haya acontecido el hecho.

Una primera interpretación acerca de la desaparición de esta sección es que los responsables de la prensa escrita han considerado que los sucesos son una temática periodística de menor entidad que otras y que un tratamiento diferenciado puede restarles seriedad o prestigio a sus páginas. Otra interpretación se encuentra en una razón puramente organizativa en las redacciones de los diarios. Los sucesos son informaciones que abarcan una actualidad muy variada y se producen en ámbitos geográficos dispares; lo que ha motivado que se hayan incluido en secciones con un enfoque más geográfico que temático ("Local", "Regional", "Nacional" o "Internacional"). Cuando la redacción no ha tenido claro dónde incluir 
un determinado suceso, ha ido directamente al "cajón de sastre" que es la sección de "Sociedad".

Otro motivo puede encontrarse en una repulsa de la prensa a los excesos del sensacionalismo con que, a veces, se han tratado estos acontecimientos, o bien como un intento de rechazo institucional a sucesos que representan una ruptura de los pactos de lectura que mantiene con la sociedad. El problema de la información de sucesos no reside tanto en su contenido temático, sino en el tratamiento que se ofrece del mismo. Puesto que las noticias de sucesos se siguen publicando y el lector continúa interesado en estos contenidos, entendemos que sí tiene sentido y es pertinente mantener este tipo de sección.

Kayser (1982: 142) considera que las informaciones de sucesos, por su contenido, son una de las más variadas:

Comporta al menos cuatro subdivisiones: catástrofes naturales, accidentes, crímenes y delitos [...] Entran en la categoría de asuntos judiciales aquellas informaciones que no tienen relación con los sucesos o con otras categorías.

El Libro de estilo del diario El Mundo (1996: 33) incluye en el área informativa de los sucesos todas aquellas informaciones sobre accidentes y desastres, delincuencia y actividades policiales (noticias relacionadas con el mantenimiento de la ley) e información judicial (tribunales). Ronda y Calero (2000: 24) seleccionan los temas más habituales que generan titulares en el periodismo de sucesos, como son los accidentes, incendios, asesinatos, explosiones, acciones violentas de grupos de jóvenes, desparecidos, agresiones sexuales y delitos sexuales con menores en la Internet.

Quesada (2007: 18) establece que los medios actuales han acotado el contenido temático de la información de sucesos a hechos y situaciones que mayoritariamente están tipificados como delitos; pero considera que la temática de los sucesos es más amplia y no se limita exclusivamente a los hechos delictivos:

Hay sucesos en los que no se produce la comisión de ningún delito, de ahí que sea prácticamente imposible establecer fronteras estrictas.

En función del tipo de suceso se establece, en definitiva, una distinción temática, que frecuentemente está relacionada con contenidos informativos sobre accidentes, delincuencia, crímenes y catástrofes naturales.

Asimismo, se evidencia que en los últimos años las páginas de los periódicos y del resto de medios han introducido nuevos contenidos temáticos, más acordes con la realidad actual y ello debido a la aparición de otros delitos relacionados con las nuevas tecnologías, el medio ambiente, el orden socioeconómico, los malos tratos o la libertad e indemnidad sexuales.

Existen, por tanto, diversas modalidades o temáticas de sucesos que impactan o conmueven a las personas en diferente grado, según la gravedad de los actos cometidos, el número de víctimas producidas o la forma de haberse producido. En este sentido, del conjunto de sucesos existentes, los medios de comunicación tienden a conceder más importancia a todos aquellos que infringen más gravemente las normas; generalmente se trata de delitos muy 
graves, tipificados por las normas penales y los que destruyen los valores de convivencia más estimados por la sociedad.

\section{Metodología}

Los datos que se recogen en este artículo, donde se describen los contenidos temáticos de la información de sucesos en la prensa, se han elaborado tomando como referencia la tesis doctoral titulada La información de sucesos en la prensa sevillana (2009). Es un análisis descriptivo y un estudio estadístico y periodístico sobre el tratamiento que ofrecen los diarios ABC de Sevilla, Diario 16 Andalucía y El Correo de Andalucía 2 .

En ese sentido, el artículo pretende hacer una aportación teórica (tomando como base unos datos estadísticos de más de 3500 sucesos) sobre las características del periodismo de sucesos en la prensa escrita.

Se explica, sobre todo, el tipo de sucesos que tiene más frecuencia de aparición en los periódicos y, por tanto, que despierta el mayor interés informativo. Este trabajo de investigación se complementa con las aportaciones teóricas recogidas de expertos y periodistas especializados en información de sucesos.

\section{Contenidos temáticos}

Los contenidos temáticos que aparecen en la prensa de sucesos suelen girar en torno a tres categorías: "delitos", "siniestros" y "otros temas". La temática de tribunales está en conexión directa con la de sucesos, pero son informaciones independientes que no se analizan en este estudio. "Tribunales" engloba noticias sobre procedimientos judiciales y juicios que tienen un tratamiento diferente, aunque los periodistas especializados en sucesos suelen ser los mismos que llevan tribunales.

La categoría "otros temas" incluye todos aquellos sucesos que no tienen cabida en "delitos", "siniestros" ni tampoco ostentan un protagonismo informativo tan relevante como los anteriores. Son noticias sobre casos insólitos y curiosos; estudios e informes; temas carcelarios y suicidios voluntarios (los inducidos se consideran penalmente homicidios).

No hay duda que las informaciones de sucesos en la prensa escrita centran su atención en los delitos y en los siniestros. La categoría temática sobre delitos difunde con mayor frecuencia sucesos referidos a homicidios, tráfico de drogas, delitos contra el patrimonio y lesiones. Por su parte, la categoría de siniestros tiene también sus preferencias informativas, ya que los tipos de sucesos que más se publican son los accidentes de tráfico, incendios y catástrofes naturales.

2.- La autora (2009) ha analizado un total de 3526 registros informativos (sucesos) y consultado 546 ejemplares de los tres diarios citados, tomando como referencia el año 1995. 
Por tanto, las informaciones más relevantes periodísticamente son todas aquellas referidas a los delitos en general, sobre todo los homicidios, debido a la espectacularidad y a la propia naturaleza del suceso, donde priman las pasiones, las emociones incontroladas, la tragedia humana, la consumación de un delito de sangre y la muerte.

El conflicto humano aparece, por tanto, como uno de los elementos característicos de la información de sucesos, ya que está asociado a los instintos primarios que acercan e identifican a los seres humanos.

Pese a que las estadísticas que ofrece anualmente la Policía reflejan que los delitos que se producen en España con mayor frecuencia numérica son contra el patrimonio (robos), sigue siendo el homicidio el tema principal de la información de sucesos, aunque se cometan en menor número.

Los siniestros ocupan igualmente un lugar muy destacado en las informaciones de sucesos, después de la delincuencia. Noticias referidas a accidentes de tráfico, accidentes laborales y catástrofes naturales son frecuentes en las páginas de los periódicos. En los siniestros aparece, además, la muerte como elemento que incrementa el interés. Cuando se producen accidentes de tráfico, el dato más difundido en los diarios es el número de fallecidos en las carreteras; en los accidentes laborales ocurre igual. En el caso de las catástrofes naturales, lo que incrementa el interés informativo de la noticia es el elevado número de víctimas que provocan los terremotos, maremotos o huracanes.

En suma, la delincuencia es la categoría temática que recurrentemente aparece en las páginas de sucesos de los diarios y el homicidio es el tipo de suceso más frecuentemente publicado (Rodríguez Cárcela, 2009: 489). La segunda categoría temática con mayor representatividad en los periódicos son los siniestros y los accidentes de tráfico el tipo de suceso más difundido. Si especificamos temáticamente, el tipo de suceso (la tipología de suceso) con mayor frecuencia de aparición las páginas de los periódicos es el homicidio; en segundo lugar, los accidentes de tráfico; en tercer lugar, el tráfico de drogas; y, por último, los delitos contra el patrimonio (robos). Detallamos a continuación estas conclusiones.

\section{Los delitos}

La categoría temática de delitos recoge todas aquellas noticias sobre delincuencia en general. En opinión de Montero y Pérez-Tornero (1986: 241), ello se debe a unas causas concretas:

Primero porque el índice de frecuencia puede fácilmente constatarse que supera a todos los demás; segundo, porque los delitos presentan el mayor grado de estereotipia y de esquematismo.

Según consideran Pérez y García (2004: 2), en un análisis sobre la evolución de los delitos en la región española de Andalucía desde 1998 hasta 2003, la percepción de la delincuencia se mide a través de dos conceptos: 
"Inseguridad ciudadana", que representa la opinión de la población respecto al nivel delictivo que se sufre en su entorno y "miedo al delito", que supone la aprehensión particular que tiene cada ciudadano de llegar a ser personalmente víctima de un delito.

Su clasificación es variada y heterogénea. Por su frecuencia en las páginas de los diarios, y teniendo en cuenta el ordenamiento penal, son noticias referidas a la comisión de delitos contra la libertad personal (amenazas, detenciones ilegales y secuestros), contra la libertad sexual (agresiones sexuales y violaciones, prostitución de menores), contra el patrimonio (robos y hurtos), entre otros.

Montero y Pérez-Tornero ( $C f$. 1986: 241) aconsejan encuadrar a este tipo de noticias relacionadas con la delincuencia en una sección específica ("Delitos"), la cual está ligada a lo que denominan "procedimientos de sanción social".

Se trata un punto de vista que valoramos, pero, como ya hemos anotado anteriormente, la información de sucesos no se limita exclusivamente a los delitos, sino que incluye otras categorías temáticas importantes que no pueden obviarse y que tienen amplio reflejo en la prensa.

El criterio que prima periodísticamente para la publicación de noticias relacionadas con la delincuencia reside en el propio carácter noticiable de este tipo de información. Los sucesos sobre delitos se refieren a acontecimientos extraordinarios que suceden a diario o casi a diario, pero no a hechos que en la rutina cotidiana afectan a nuestra sociedad. Rigen además otros criterios generales que dominan la presentación de este tipo de informaciones en la prensa escrita, como son la inmediatez, la novedad, el impacto social, la sorpresa, la violencia, el conflicto de intereses y la transgresión de la norma social y legal.

Los diversos expertos que han tratado el tema de la crónica delictiva o la información sobre la delincuencia coinciden al afirmar que existe un modo particular de construir las noticias que se insertan en esta temática.

Montero y Pérez-Tornero ( $C f$. 1986: 241 y ss.) recogen cuatro criterios específicos que establecen la noticiabilidad de los acontecimientos y organizan la selección de los hechos. Son los siguientes: a) la seriedad del daño; b) las circunstancias anecdóticas que rodean el caso (humor, ironía, rareza); c) las circunstancias dramáticas o sentimentales; y d) la implicación de algún famoso o de alguna persona de estatus elevado.

Las estadísticas de seguridad elaboradas por el Cuerpo Nacional de Policía de España muestran una clasificación de hechos que atentan contra la seguridad ciudadana. La mayoría son delictivos, tipificados en el Código Penal, y el resto son calificados como "Faltas", "Otra infracción" o "Sin infracción".

Nos referimos concretamente a un informe elaborado por el Ministerio del Interior en relación al quinto estudio de las Naciones Unidas sobre Tendencias Delictivas y Funcionamiento de los Sistemas de Justicia Penal (1990-1994). Los tipos delictivos enumerados son los siguientes: a) contra la propiedad; b) contra las personas; c) contra la libertad sexual; $d$ ) contra la libertad/seguridad; e) contra la administración/justicia; f) contra la legislación especial; g) contra la seguridad interior del Estado; $h$ ) utilización ilegítima de vehículos 
motorizados; $i$ ) de riesgo; $j$ ) de falsedad; $k$ ) otras infracciones penales; $l$ ) otras infracciones y otros hechos (España, Ministerio del Interior, 1994: 8-11).

Gran parte de estos hechos se ha convertido en noticias y tienen su plasmación directa en las informaciones de sucesos. En concreto, se refieren a delitos-noticias contra la propiedad o el patrimonio (robos, hurto, tenencia de útiles para robo, estafa inmobiliaria y bancaria; apropiación indebida, otras defraudaciones; expedición de cheques en descubierto; incendios y daños intencionados); contra las personas (homicidios, asesinatos, inducción al suicidio, aborto y lesiones en general); contra la libertad sexual (violación, agresión sexual, exhibicionismo y provocación sexual; corrupción de menores, rapto, proxenetismo; trata de blancas y otros relativos a la prostitución); de riesgo (fabricación o producción de drogas; tenencia y tráfico de drogas; y contra la seguridad del tráfico); utilización ilegítima de vehículos de motor (apropiación indebida, con intimidación y sin intimidación); y otros hechos (recuperación de objetos de procedencia desconocida, desaparición de personas, fuga de menores, suicidios, muerte por sobredosis y descubrimiento de cadáveres).

En cuanto al número de delitos consignados en las estadísticas penales, aparecen reflejados el homicidio, contra la libertad sexual (violaciones), contra la libertad sexual (resto), lesiones graves, robos con agravantes (violencia o fractura), robos de automóviles, otros robos, estafas, relativos a falsificación de moneda, relativos a estupefacientes y otros.

Los cuatro delitos indicativos de conductas violentas son, en opinión de la INTERPOL, los homicidios, delitos contra la libertad sexual (fundamentalmente violaciones), lesiones graves y robos con violencia e intimidación. Del total de los citados delitos, la tasa española (2.75 $\%$ ) está por debajo, aunque próxima, a la media europea (2.91\%). "No obstante, los datos reflejan que nuestra tasa está incrementada fundamentalmente por el alto volumen de robos violentos (la tasa más alta de Europa), en tanto que nuestros niveles de homicidios, agresiones sexuales y lesiones son de los más bajos" (España, Ministerio del Interior, 1994: 11).

Dentro del conjunto de informaciones sobre delincuencia, vemos, por tanto, que son los denominados por el Código Penal vigente "Delitos contra el patrimonio y el orden socioeconómico" (Título XIII. Artículos 234 al 304) los que se cometen mayoritariamente $\mathrm{y}$, por tanto, se difunden con más frecuencia. Sobre todo hablamos de sucesos que informan sobre los delitos de robo, hurtos, extorsiones, robos y hurtos de vehículos, usurpación y defraudaciones (estafas y apropiaciones indebidas).

Este dato coincide con un estudio sobre la delincuencia en España (1993-2003), realizado por el Instituto Universitario de Investigación sobre Seguridad Interior, donde se pone de manifiesto que los delitos más representativos estadísticamente son contra el patrimonio y contra las personas. Son precisamente los delitos contra el patrimonio los que marcan la pauta general, ya que cada vez que aumenta o disminuye este tipo de delito, esta tendencia se ve reflejada en el total general de las estadísticas.

También tienen cabida en esta clasificación otros delitos como las estafas o los hurtos, pero con menor reflejo en la prensa que los robos. Se trata de los daños causados de forma imprudente, de los delitos relativos a la propiedad intelectual e industrial; al mercado y a los consumidores; de los delitos societarios; de la receptación de objetos robados y de la alteración de precios en concursos y subastas públicas. 
Los delitos de homicidio (aunque hemos constatado con las estadísticas policiales que no son los que mayoritariamente se producen) sí son los que más interés periodístico despiertan, por la gravedad del hecho cometido y el impacto social que provocan. Debido a la relevancia que esta temática delictiva tiene en la información de sucesos, vamos a estudiarla a continuación de forma independiente.

Dentro del amplio campo de la información delictiva, los delitos contra la libertad e indemnidad sexuales tienen un amplio reflejo en las páginas de los periódicos. Se trata de noticias impactantes por su contenido donde el sexo ocupa un lugar preeminente: agresiones sexuales, abusos sexuales, acoso sexual, exhibicionismo y provocación sexual, prostitución y corrupción de menores; sin olvidar los crímenes sexuales, que entrarían dentro del capítulo de los delitos de homicidio, que vamos a examinar a continuación.

Carl Warren (1979: 437) considera que el sexo se proyecta profundamente en las noticias de sucesos y tribunales:

Forma parte integrante, probablemente de un tercio de las noticias generales de un periódico normal y, en algunos casos, llena frecuentemente la primera página bajo grandes titulares.

El tráfico de drogas es, dentro de la categoría temática de delitos, el tipo de noticia que ocupa el segundo lugar en cuanto a su reflejo en las páginas de los periódicos y en los medios de comunicación en general. Estos sucesos, desde el punto de vista jurídico, se denominan genéricamente como "Delitos contra la Salud Pública", que el Código Penal de 1995 recoge en sus artículos 359 a 378 (Capítulo III).

En esta modalidad temática se incluyen todo tipo noticias referidas a actividades de cultivo, elaboración, tráfico, comercialización, posesión y consumo ilegal de drogas tóxicas, estupefacientes o sustancias psicotrópicas.

Según se observa en el gráfico 1, son los homicidios la temática que presenta una mayor frecuencia de aparición en prensa escrita, registrando un total de 474 sucesos, lo que representa el 27\% del total de los 1757 delitos computados (Rodríguez Cárcela, 2009: 234). La cuantificación de los 3526 sucesos analizados pone de manifiesto que, dentro de la categoría o variable temática de "Delitos", son los homicidios los que ocupan el primer lugar en cuanto al mayor número de informaciones publicadas en conjunto en los tres diarios analizados.

Por tanto, en la información de sucesos de la prensa, se constata que la temática predominante es la referida a los “delitos" y, dentro de estos, el que aparece publicado más frecuentemente es el delito de homicidio (un total de 474 registros), mayoritariamente referidos a asesinatos o conocidos comúnmente como crímenes. La segunda subcategoría temática es la de referida a delitos de tráfico de drogas: un total de 416 sucesos que suponen el $23 \%$ de esta variable.

La tercera subcategoría es la de delitos contra el patrimonio, que registra 392 sucesos (representa el $22.3 \%$ ), sobre todo informaciones sobre robos, hurtos y estafas. El cuarto lugar lo ocupan los sucesos sobre delitos de lesiones (171 informaciones registradas, un 
9.7\%), el quinto lugar la subcategoría de delitos contra la libertad sexual (147 registros, un $8.4 \%$ ) y en sexto lugar noticias sobre inmigración clandestina y extranjería (60 registros).

Gráfico 1: Variable temática - Delitos

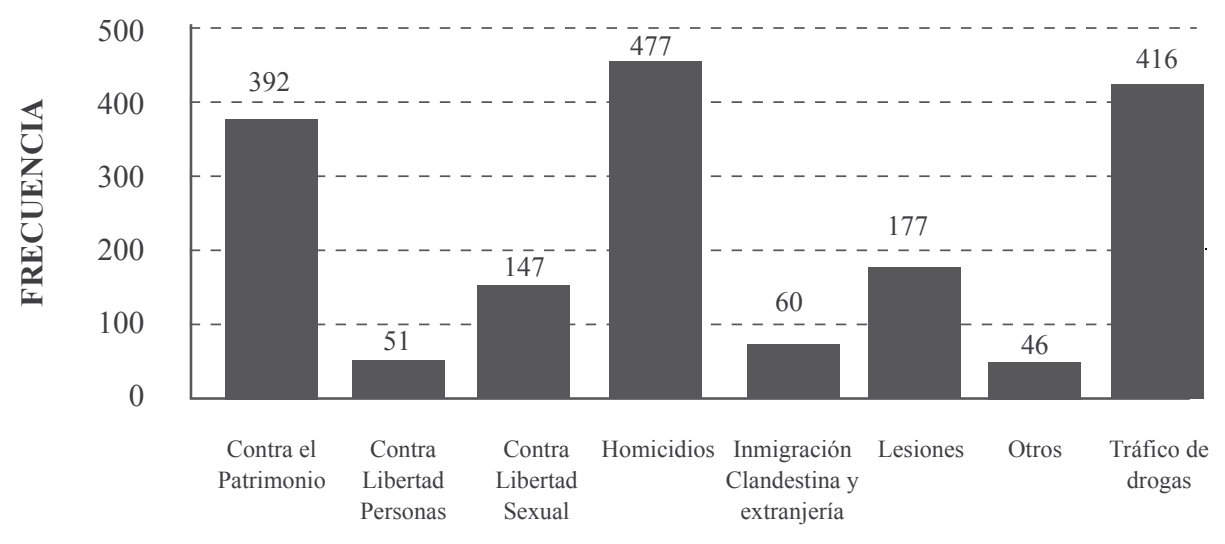

Fuente: Elaboración propia.

\subsection{Los homicidios}

Es el tipo de suceso que con mayor frecuencia publican los periódicos. O dicho de otro modo, es la información de sucesos con mayor protagonismo en la prensa escrita ${ }^{3}$. Incluye noticias referidas tanto al delito específico de asesinato como al genérico de homicidio ${ }^{4}$.

El análisis de los sucesos permite indicar que mayoritariamente las informaciones encuadradas en esta temática se refieren a asesinatos y que los diarios los denominan, de forma común, como "crímenes". Los sucesos recogen y describen los hechos que han acontecido relacionados con los homicidios en general, pero no tipifican el delito en sí, como es natural, puesto que dicha misión es competencia de los jueces y no de los periodistas.

Dentro del variopinto contenido de noticias relacionadas con los delitos, se puede considerar que son los homicidios (en general) y los asesinatos (en particular) la temática más importante o destacada en el periodismo de sucesos. Sin lugar a dudas, podemos

3.- Los principales temas que publica $A B C$ de Sevilla son (por orden de frecuencia): los homicidios, los accidentes de tráfico, los delitos contra el patrimonio y el tráfico de drogas. En El Correo de Andalucía son los referidos a los homicidios y el tráfico de drogas. En cambio, en Diario 16 Andalucía son los sucesos sobre el tráfico de drogas, los accidentes de tráfico, los homicidios y los delitos contra el patrimonio los más recurrentes. En promedio, prevalece la temática de homicidios como suceso con mayor frecuencia de aparición (Rodríguez Cárcela, 2009: 489-490).

4.- El Código Penal español recoge las siguientes formas de homicidio: a) homicidio imprudente, el acto de matar a otro por imprudencia; $b$ ) asesinato, matar a otro con alevosía, por precio o con ensañamiento; y $c$ ) suicidio, si ha existido inducción y cooperación. 
afirmar que estos hechos (que implican el deceso de una persona) conforman el tipo de suceso informativamente más relevante de esta especialidad periodística.

El motivo reside no sólo en que es un tipo de suceso que despierta gran interés general y tiene un amplio alcance social, sino porque los periodistas priorizan aquellos sucesos que infringen gravemente las leyes y normas sociales. El homicidio es uno de los delitos de mayor gravedad tipificado en la normativa penal, ya que supone quitar la vida de otra persona que es el bien más preciado que tiene.

La gravedad del suceso cometido y la importancia periodística que se le concede al mismo se incrementa si al matar a otro concurren las circunstancias de alevosía, ensañamiento, precio, recompensa o promesa. El asesinato es el suceso más grave y siempre es noticia de primer orden en los medios. Este tipo de suceso se conoce genéricamente en los medios de comunicación bajo la denominación de crimen; es decir, como un acto o delito grave que conlleva derramamiento de sangre.

De esta forma, bajo el punto de vista policial, los crímenes tratan de sucesos o hechos relacionados con delitos de sangre que atentan gravemente contra las personas, como son los homicidios, asesinatos, suicidios, lesiones y otros ${ }^{5}$. Desde el punto de vista periodístico, la información de crímenes se refiere comúnmente a los asesinatos y las lesiones que atentan gravemente contra la integridad física de las personas, pero ya hemos señalado que es más correcto delimitar el término con la expresión "homicidio", especificando "asesinato" cuando se haya cometido de forma dolosa. La temática criminal que aparece reflejada en los periódicos es, por tanto, muy variada, ya que por extensión también incluyen delitos graves cometidos contra las personas que comúnmente conllevan derramamiento de sangre ${ }^{6}$.

Los sucesos que informan sobre homicidios son los que despiertan mayor interés en los lectores y en la audiencia, ya que pueden llegar a provocar alarma social. Además, son actos antisociales que suponen no sólo el infringir la ley en su forma más grave, sino la manifestación más depredadora de la violencia.

Montero y Pérez-Tornero ( $C f$. 1986: 241 y ss.) destacan que los delitos menos frecuentes en las estadísticas policiales (como son los homicidios) son los que reciben mayor atención en el diario El País y que la radio y la televisión dedican mucho más espacio que la prensa escrita a tratar estos delitos. Es una afirmación que se corrobora en el análisis estadístico de los sucesos analizados en los diarios $A B C$, El Correo y Diario 16, donde los homicidios son el tipo de sucesos que aparece con mayor frecuencia.

En ese sentido, Martínez Albertos (1983: 367) estima que los homicidios son el tipo de noticia más destacada de la información de sucesos:

Son los hechos sangrientos y los crímenes morbosos -las dos eses del periodismo francés: sang y sein- los que se llevan la parte del león en los contenidos particulares de la crónica de sucesos.

5.- Clasificación establecida de las fichas estadísticas de las actuaciones policiales, donde aparece una tipificación de hechos delictivos y que afectan a la seguridad ciudadana (España, Ministerio del Interior, 1994: 10-12).

6.- En este tipo de informaciones es recomendable tener en cuenta la presunción de inocencia sobre todo en los casos en cuales la autoría de los hechos está pendiente de una decisión judicial. 
Pérez Abellán (1997: 13) explica que los asesinatos provocan un enorme interés y una fascinación, que afecta a todas las clases sociales, ya que todos quieren saber las razones de un hecho criminal y conocer la psicología del asesino. Considera que los que causan más impresión entre los lectores son los asesinatos múltiples, por el número de víctimas afectadas:

El crimen ejerce una poderosa fascinación sobre la gente en general, que no se debe, como pudiera pensarse, a un interés morboso sino simplemente a la sorpresa espectacular que produce el ejercicio del poder de matar, el más terrible que existe.

Warren (Cf. 1979: 411) indica siete factores básicos que convierten un asesinato en noticia: la importancia de las personas (la riqueza y la posición social tienen siempre interés periodístico, especialmente cuando existen indicios de algo turbio); la importancia de los lugares; las pérdidas económicas (son un factor significativo en el valor de las noticias); la acción y muchedumbre (otorgan dramatismo); el misterio y suspense (mantiene despiertos e interesados a los lectores); las circunstancias únicas (cualquier elemento nuevo, peculiar o sorprendente refuerza el impacto de la noticia, especialmente cuando está relacionado con los motivos del acto criminal); y el contenido emocional (el interés humano y el juego de los sentimientos intervienen en la conformación de los hechos criminales).

A un nivel más profundo que cualquiera de estos factores citados, Warren ( $C f$. 1979: 412) añade que se encuentran otras situaciones que constituyen la corriente fundamental de los sucesos criminales, como son el racismo, las disputas laborales, la rivalidad política, las peleas conyugales o de pareja, la corrupción, la sed de poder y las riquezas.

Dentro de la información de sucesos existen periodistas expertos en homicidios. El mencionado autor (1979: 421) estima que, al igual que los diarios emplean expertos en política, deportes, ciencia o economía, los hechos luctuosos necesitan igualmente el conocimiento de un especialista:

Una buena información criminal exige algo más que una fuerte dedicación y el uso del sentido común. Es preciso además tener experiencia y una gran familiaridad con los métodos policíacos y con las actividades y las características criminales de una determinada comunidad.

Se trata de una especialización periodística que, por la temática de las noticias, supone un trabajo riguroso, duro y (a veces) desagradable. Sin embargo, un buen trabajo periodístico en esta materia (bien documentado, donde se analizan los hechos, las causas y las posibles soluciones) puede contribuir a la prevención de nuevos homicidios. Estas informaciones periodísticas (donde se ahonda en el porqué y el cómo de un determinado homicidio) suponen un verdadero trabajo de investigación e importante fuente de datos para criminalistas, sociólogos y equipos policiales.

En esta línea, Bernal Rodríguez (Cf. 2001: 149 y ss.) cree que el lector espera que la prensa, a través de sus investigaciones, contribuya a descifrar el enigma de un caso sangriento no resuelto, que el trabajo del reportero o del cronista explique las causas que provocan el crimen y la exigencia social de que se apliquen mecanismos de reparación social. Se aprecia, pues, que los lectores esperan del periodista de sucesos que cumpla una correcta labor de investigación que el propio ejercicio de su profesión exige. 
Una buena parte de la información que recaba el periodista experto en crímenes proviene de la Policía, mediante el seguimiento de las investigaciones policiales iniciadas, la lectura de los atestados y las denuncias.

\section{Los siniestros}

Esta categoría temática incluye sucesos sobre accidentes en general, así como de acontecimientos catastróficos que suponen pérdidas humanas y materiales. En definitiva, informaciones publicadas sobre daños y destrucciones que sufren las personas y sus propiedades por causa de muerte accidental, incendio, naufragio, factores climáticos o de catástrofe natural.

Los sucesos sobre siniestros incluyen noticias muy variadas y llamativas; las que tienen mayor repercusión en la prensa escrita son las referidas a accidentes de tráfico, catástrofes naturales e incendios.

Según recoge el gráfico 2, esta categoría temática es la segunda en importancia en la información de sucesos, después de la de delitos. Contabiliza 1129 sucesos que representan el 32\% de esta variable (Rodríguez Cárcela, 2009: 237)

La subcategoría de temática “accidentes de tráfico" es la primera en importancia informativa, ya que contabiliza 451 sucesos y supone el 39.9\% de esta categoría. La subcategoría "otros accidentes" ocupa el segundo lugar en cuanto al número de sucesos publicados y tiene una frecuencia de 311 registros que representan el 27.5\%. La subcategoría "incendios" registra el tercer lugar de frecuencia informativa, computando 225 sucesos que suponen el 19.9\% de esta categoría. Por último, la subcategoría temática que presenta una frecuencia más baja de aparición es la de "catástrofes naturales", con 142 sucesos (12.6\%).

Gráfico 2: Variable temática - Siniestros.

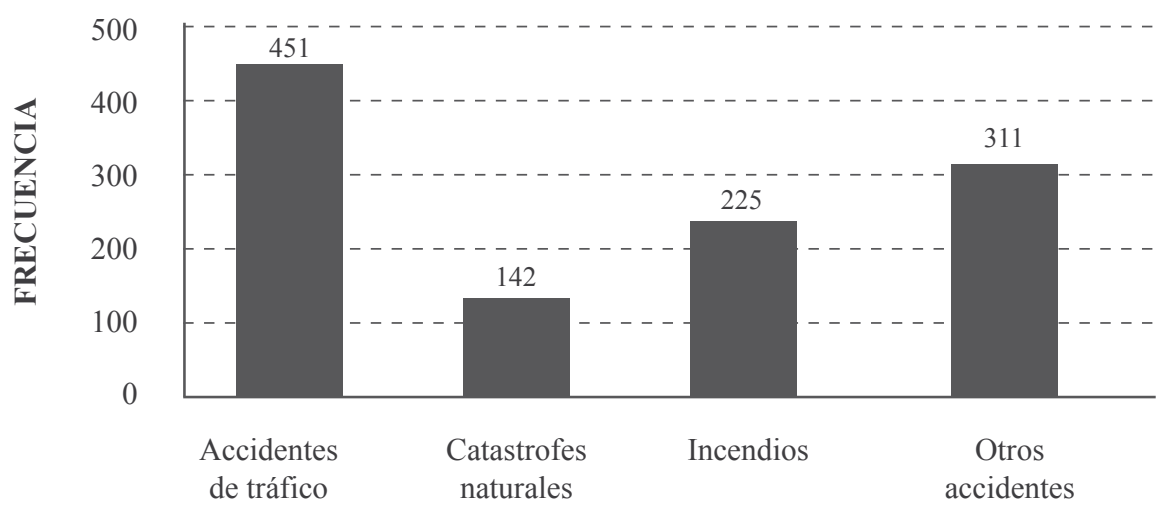

Fuente: Elaboración propia. 
"Otros accidentes" recoge sucesos referidos a siniestros muy variados, donde un elemento sorpresa provoca o da origen al accidente. En estos se registran víctimas, heridos y muertos, pero causadas no de forma natural, sino por la actuación del hombre o la intervención de los animales: accidentes laborales, domésticos, entre otros. Los sucesos referidos a los incendios ocupan parte destacada de la temática de siniestros.

Las catástrofes naturales son informaciones espectaculares con víctimas y daños materiales considerables. Son "hechos-ruptura", debido a su gravedad y centralidad, y "explosiones" informativas, cuya importancia se mide por el número de muertos. Estos términos ("hechos-ruptura" y "explosiones") están recogidos de Bernal (2001) y Gomis (1991) respectivamente. Dichos autores (en sus respectivos análisis sobre la información de sucesos) estiman que hay noticias que, por su carácter excepcional y catastrófico, acaparan el protagonismo en los medios de comunicación.

Las noticias sobre catástrofes naturales tienen menos frecuencia de aparición en las páginas de los periódicos, aunque adquieren un protagonismo importante en las páginas de sucesos cuando acontece un siniestro. El motivo obedece a que este tipo de siniestros ocurren, afortunadamente, en menor número que el resto de los citados y, por ello, tienen menor frecuencia de aparición en la prensa. Sin embargo, debido a su espectacularidad y el número de víctimas que provoca, cuando se producen ocupan gran espacio y tratamiento en la prensa y en el resto de medios.

Las catástrofes provocadas o inducidas por el ser humano, como los atentados al medio ambiente, las contaminaciones masivas, las masacres o los genocidios suelen traspasar el ámbito de los sucesos para tener otra consideración periodística más genérica e incluirse en temas políticos, de sociedad o medioambientales.

\subsection{Los accidentes de tráfico}

Son, junto a los homicidios, las informaciones de sucesos que más protagonismo tienen en los periódicos. Si de la temática de delitos son los homicidios, los sucesos más relevantes dentro de los siniestros son los accidentes de tráfico. Ello se debe a que este tipo de accidentes reúnen todos los ingredientes periodísticos para dispensar un amplio tratamiento informativo: se producen diariamente; genera víctimas y decesos; tienen una gran aparatosidad; las imágenes son de gran impacto visual y despiertan alarma social. Además, el número de accidentes se incrementa mayoritariamente durante los fines de semana y el periodo vacacional.

A modo de ejemplo, recogemos una frase que encabeza la entradilla de una crónica de $A B C$ de Sevilla sobre este tema:

Dos accidentes de autocar, en Lérida y Córdoba, han teñido de sangre las carreteras españolas el pasado fin de semana $(8 / \mathrm{V} / 1995$, p. 86$)$

Otra característica que define este tipo de noticias es que, en la mayoría de los casos contabilizados, no se facilitan las causas concretas que provocaron los accidentes. Esto tiene una justificación, puesto que las circunstancias que causan los accidentes requieren 
de una investigación policial y judicial posterior al accidente y el periodista no dispone de esos datos hasta días después del siniestro.

No obstante, algunas noticias sí recogen claramente las causas específicas del accidente (el mismo día en que ha pasado) debido a que son casos muy evidentes, como los atropellos. En este sentido, veamos varios ejemplos con los siguientes titulares:

Un conductor asesino causa cinco heridos graves en Asturias (ABC de Sevilla, 23/IV/1995, p. 86).

Fallece un hombre tras ser arrollado por una motocicleta en la calle Luis Montoto $(A B C$ de Sevilla, 23/4/1995, p. 88).

Una mujer muerta y toda su familia herida al ser arrollados por un camión que se dio a la fuga (ABC de Sevilla, 3/V/1995, p. 63).

En estos casos, los hechos cometidos son delitos ("imprudencia temeraria" y "homicidio") pero se han mantenido dentro de "siniestros", ya que se trata de accidentes de tráfico que tienen como resultado la comisión de delitos.

Los datos que se reflejan en las informaciones de accidentes de tráfico son los relativos tanto al número de heridos como de muertos, así como el lugar (e incluso la hora) donde se produjo el siniestro. Sirvan como ejemplos los siguientes párrafos recogidos de varias noticias publicadas:

En las carreteras andaluzas, según informó Tráfico a $A B C$, se han registrado desde que comenzó la operación especial el viernes día 7, a las 15 horas, ya hasta ayer domingo, día 16 a las 20 horas, un total de 20 accidentes de tráfico en las carreteras de la Comunidad Autónoma, con el resultado de 22 víctimas mortales, 11 heridos graves y 14 leves (ABC de Sevilla, 17/IV/1995, p. 63).

El accidente más grave se produjo en el término municipal de Lucena (Córdoba), a la altura del kilómetro 67 de la N-331, donde una colisión entre dos vehículos registrada a las 02:20 horas de ayer provocó la muerte de dos personas y heridas graves a otras dos (El Correo de Andalucia, 25/IX/1995, p. 10)

Ocho senegaleses han resultado heridos, seis de ellos de carácter grave, en un accidente de tráfico ocurrido en el término municipal de La Carlota, en Córdoba, al volcar en la calzada la furgoneta que ocupaban. El siniestro ocurrió el jueves en la Autovía de Andalucía, cuando, por causas no precisadas, volcó la furgoneta SE-2271-BX, que circulaba hacia Madrid (Diario 16 Andalucia, 8/VII/1995, p. 16).

También es característico de la prensa que publiquen los lunes las noticias sobre los informes o resultados de los accidentes producidos durante el fin de semana, según los datos que facilita habitualmente la DGT. Así, por ejemplo, enumeramos cuatro titulares del lunes 15 de mayo de $1995^{7}$ :Tráfico. Cuatro muertos en las carreteras andaluzas durante el pasado fin de semana (Diario 16 Andalucía, p. 14).

7.- Se puede comprobar que los diarios $A B C$ de Sevilla y El Correo de Andalucía difieren en cuanto al número de heridos. Parece ser que es 4 el número de heridos correcto, ya que Diario 16 de Andalucía, en el desarrollo de la noticia, también indica la misma cantidad de heridos, según han recogido los tres periódicos de fuentes de la DGT o de agencias de prensa que citan a la Dirección General de Tráfico. 
Cuatro muertos y nueve heridos en las carreteras de semana el fin de semana ( $A B C$ de Sevilla, p. 79).

Cuatro muertos y cuatro heridos en accidentes de tráfico este fin de semana (El Correo de Andalucia, p. 10).

Cincuenta y seis muertos en las carreteras andaluzas durante el mes de julio (ABC de Sevilla, p. 72).

\section{Conclusiones}

El periodismo de sucesos informa mayoritariamente de noticias luctuosas. También, en mayor medida, de hechos curiosos y extravagantes. Este dato es bastante clarificador para conocer y establecer las características de este tipo de información periodística especializada. Se trata de informaciones relacionadas con todas aquellas actuaciones que están fuera de la norma social y de las leyes.

El suceso es generalmente transgresor y supone una ruptura de la normalidad y de la convivencia social. La violencia y la delincuencia son elementos consustanciales en el periodismo de sucesos. De ahí, que los sucesos informen a los lectores y al público en general sobre el quebrantamiento o la violación de una ley, una costumbre, una norma.

Lo que les otorga a las noticias su carácter de suceso es un elemento de sorpresa, de choque, de ruptura de la previsible actualidad cotidiana. Como hemos indicado, la esencia de la mayoría de los sucesos es negativa, pero puede nutrirse además de hechos raros o extraños.

La mayoría de los autores consultados coinciden al afirmar que la característica fundamental que distingue al periodismo de sucesos es su "interés humano" y el reflejo de la conducta del ser humano en su vertiente más negativa e irracional.

Otro elemento característico que se le ha achacado históricamente (de forma generalizada, como un tópico) al periodismo de sucesos es el sensacionalismo. Creemos que, en ocasiones, se trata de un elemento añadido, pero ni mucho menos principal ni definitorio de los sucesos, en el que puede degenerar este tipo de información si se exageran sus contenidos o si se busca (a toda costa) incrementar el número de lectores.

Por este motivo, entendemos que existe una confusión al tratar de identificar el periodismo de sucesos con el sensacionalismo o "amarillismo", ya que el primero es una especialidad o un género connatural al periodismo. La información de sucesos trata los hechos y acontecimientos más humanos, habitualmente en su vertiente más negativa, $\mathrm{y}$, por este motivo, de mayor interés general.

La información de sucesos debe ser abordada con responsabilidad profesional, sobre todo teniendo en cuenta que se trata de una especialidad periodística que informa sobre hechos violentos, conflictivos y de elevado contenido emocional que son habitualmente seguidos por los lectores.

El periodismo de sucesos no es por sí mismo morboso, pero indudablemente sí lo son ciertos temas que necesitan de un tratamiento serio y riguroso, alejado de cualquier 
sensacionalismo. Especialmente nos referimos a la difusión de sucesos sobre asesinatos, violaciones y agresiones sexuales, abusos a menores y pederastia en general.

La recomendación genérica que hace la mayoría de los expertos es respetar los códigos deontológicos y los libros de estilo, guardando especial atención a la presunción de inocencia. La premisa fundamental es la necesidad de brindar información veraz y responsable.

El cumplimiento de los principios deontológicos y el desempeño de un ejercicio profesional responsable en el tratamiento de los sucesos están muy condicionados por el estilo informativo de cada medio y la política empresarial que desarrolla.

La responsabilidad profesional favorece que el periodista que redacta los contenidos evite los detalles morbosos, el uso de un lenguaje truculento y melodramático o la publicación innecesaria de imágenes que puedan dañar la sensibilidad de los lectores, vulnerar la intimidad o el honor de las víctimas.

Un tratamiento responsable no significa dosificar o disminuir la presencia de los sucesos, sino saber difundirlos adecuadamente, exponiendo los hechos, pero sin caer en la exageración de los detalles o la invención de lo ocurrido. Existen noticias de sucesos porque todos los días ocurren siniestros, hechos delictivos y sangrientos y esta realidad no puede obviarse en los medios de comunicación. La solución se centra en una selección, un espacio y un tratamiento adecuados.

Por tanto, es innecesaria la ocultación de la información de sucesos en los periódicos. Los ciudadanos tienen derecho a estar informados, aunque las noticias sean trágicas o desagradables. Censurar equivaldría a engañar a los lectores, transmitiéndoles una falsa sensación de seguridad.

\section{Fuentes consultadas}

AA. VV.

_(1999). Diccionario Jurídico Espasa. Madrid: Fundación Tomás Moro.

_(1996). Libro de estilo de El Mundo. Madrid: Ediciones Temas de Hoy.

Bernal Rodríguez, M. (2001). "La crónica de sucesos entre dos seducciones: sensacionalismo y literatura”, pp. 146 y ss. En AA. VV.: Periodismo: propuestas de investigación. Sevilla: Padilla Editores \& Libreros.

Calero, J. M. y Ronda, J. (2000). Manual de periodismo judicial. Sevilla: Grupo de Investigación en Estructura, Historia y Contenidos de la Comunicación de la Universidad de Sevilla.

España. Ministerio del Interior (1994). Informe estadístico de denuncias presentadas ante los Cuerpos de Seguridad del Estado. Madrid: Instituto de Estudios de Policía.

España. Jefatura del Estado (1995). Boletín Oficial del Estado (BOE) $N^{o}$ 281: Ley Orgánica 10/1995. 
Gomis, L. (1991). Teoría del periodismo. Cómo se forma el presente. Barcelona: Paidós.

Hare, R. (2000). “La naturaleza del psicópata”, p. 24. En AA. VV. Violencia y psicopatía. Barcelona: Ariel.

Kayser, J. (1982). El diario francés. Barcelona: A. T. E.

Marlasca, M. y Rendueles, L. (2002). Así son, asi matan. Madrid: Temas de Hoy.

Montero, Ma D. y Pérez-Tornero, J. M. (1986). “La crónica de delitos en El País”, pp. 230-250. En Imbert, G. y Vidal Beneyto, J, (coords.). El País o la referencia dominante. Barcelona: Mitre.

Pérez Abellán, F. (1997). Crónica de la España negra. Madrid: Espasa.

Pérez Jiménez, F. y García España, E. (2004). La evolución de la delincuencia en Andalucía. Boletín Criminológico $N^{o} 75$, agosto-septiembre. Málaga: Instituto Andaluz Interuniversitario de Criminología, sección de la Universidad de Málaga.

Quesada, M. (2007). Periodismo de sucesos. Madrid: Síntesis.

Real Academia Española (2001). "Crimen”. Diccionario de la Lengua Española, vigésima segunda edición. Extraída el 12/IX/2011 desde http://buscon.rae.es/draeI/

Rodríguez Cárcela, R. (2009). La información de sucesos en la Prensa sevillana [Tesis doctoral]. Sevilla: Facultad de Comunicación de Universidad de Sevilla. Extraída el 11/IX/2011 desde http:// fondosdigitales.us.es/tesis/tesis/1006/la-informacion-de-sucesos-en-la-prensa-sevillana/

Sanmartín, J. (2000). “Concepto e historia del asesino en serie”, p. 135. En AA. VV. Violencia y psicopatía. Barcelona: Ariel.

Silva, L. (2002). “Esa fantástica realidad”, p. 19. En Marlasca, M. y Rendueles, L. Así son, así matan. Madrid: Temas de Hoy.

Warren, C. (1979). Géneros periodísticos informativos. Barcelona: A. T. E. 